\title{
RA?EGA
}

O ESPACYO GEOGRÁFICO EM ANÁLISE

\section{ANÁLISE DIRECIONAL DA EXPANSÃO URBANA DE CIDADES DE PORTE MÉDIO: UMA APLICAÇÃO DA DIMENSÃO FRACTAL}

\section{DIRECTIONAL ANALYSIS OF URBAN SPRAWL IN MEDIUM-SIZED CITIES: AN APLICATION OF FRACTAL DIMENSION}

\author{
Gracieli Trentin \\ Professora da Universidade Federal do Rio Grande (FURG) \\ Instituto de Oceanografia \\ São Lourenço do Sul, RS \\ e-mail: gracitrentin@gmail.com \\ Marcos César Ferreira \\ Professor da Universidade Estadual de Campinas (UNICAMP) \\ Instituto de Geociências \\ Campinas, $S P$ \\ e-mail: macferre@ige.unicamp.br
}

Recebido em: 27/06/2014

Aceito em: 15/10/2014

\section{Resumo}

A irregularidade das áreas urbanas traz a necessidade de novas formas de análise que considerem a morfologia urbana e não somente sua área ocupada. O objetivo deste trabalho foi identificar e caracterizar a forma de cidades de porte médio, utilizando a estimativa da dimensão fractal (D) pela densidade de ocupação a partir da análise setorial das formas urbanas em quatro datas de análise: 1938, 1985, 1995 e 2005. Adicionalmente, foram considerados os aspectos de topografia e as características de uso e ocupação do solo na borda urbana, os quais foram relacionados aos valores calculados de D. Para este estudo foram selecionadas as cidades de São José do Rio Preto e o aglomerado urbano de Jundiaí-Várzea Paulista, ambas no estado de São Paulo. As áreas urbanas foram identificadas por meio de mapas históricos e imagens do satélite LANDSAT TM 5 . Círculos concêntricos com intervalos de $500 \mathrm{~m}$, posteriormente divididos em setores direcionais de $45^{\circ}$, foram sobrepostos às áreas urbanas, o que possibilitou a 


\title{
ANÁLISE DIRECIONAL DA EXPANSÃO URBANA DE CIDADES DE PORTE MÉDIO: UMA APLICAÇÃO DA DIMENSÃO FRACTAL
}

obtenção dos valores de $\mathrm{D}$, considerando o afastamento em relação ao centro urbano. As assinaturas fractais mostraram o maior preenchimento urbano na área central de cada cidade e fragmentação em direção às bordas. Os valores de $D$ para os setores direcionais apontaram a maior fragmentação urbana do aglomerado Jundiaí-Várzea Paulista, em vista de sua forma urbana alongada, da influência do sistema viário e da presença de impedâncias espaciais representadas por suas características topográficas e de sítio urbano.

Palavras-chave: análise espacial, forma urbana, uso da terra, cartografia.

\begin{abstract}
The irregularity of urban areas brings the need of new methodologies that consider the urban morphology and not only the occupied area. The aim of this paper was to identify and characterize the urban form of medium-sized cities. For this, we use the fractal dimension estimative (D) by means of occupation density from sector analysis of urban form in four dates: 1938, 1985, 1995 and 2005. Additionally, were considered the topographic aspects and land use characteristics of urban edge, which were related to $D$ values calculated. In this study were selected the cities of São José do Rio Preto and the urban agglomeration of Jundiaí-Várzea Paulista, both in São Paulo State. The urban areas were identified by historical maps and satellite images of LANDSAT TM 5. Concentric circles at intervals of $500 \mathrm{~m}$, divided into directional sectors of $45^{\circ}$, were overlapping to urban areas to obtain the $D$ values, considering the distance from urban center. The fractal signatures showed higher fragmentation from center area of the cities to the edge. The $D$ values to directional sectors indicated the largest urban fragmentation in the urban agglomeration of Jundiaí-Várzea Paulista, due to the most elongated form, influence of road system and the presence of spatial impedances linked with its topographical and urban site characteristics.
\end{abstract}

Keywords: spatial analysis, urban form, land use, cartography.

\section{INTRODUÇÃO}

$O$ século $X X$ foi marcado pela maior taxa de crescimento demográfico na história da humanidade. Entre os anos de 1950 e 2000, a população mundial aumentou de 2,6 para 7 bilhões de pessoas. Esta elevação demográfica ocorreu paralela ao enorme crescimento da taxa de urbanização mundial. O século XXI mantém o contínuo avanço da urbanização, tanto que resultou na maioria da população mundial vivendo em áreas urbanas (RODRIGUES, 2009; ONU, 2011). 


\section{ANÁLISE DIRECIONAL DA EXPANSÃO URBANA DE CIDADES DE PORTE MÉDIO: UMA APLICAÇÃO DA DIMENSÃO FRACTAL}

A concentração populacional nas cidades reforça a preocupação quanto ao crescimento das áreas urbanas e, principalmente, quanto à morfologia deste crescimento, de modo disperso nas áreas periféricas, o que tende a ocupar áreas anteriormente destinadas à agricultura e, ao mesmo tempo, dificultar e elevar os custos de distribuição de serviços básicos à população. Torrens e Alberti (2000) ressaltam que a ocupação a partir da mancha urbana apresenta vários impactos negativos sobre a cidade, como nos transportes, ocupação de áreas ambientalmente frágeis, baixa densidade de ocupação, além de esforços desnecessários quanto ao provimento de serviços e infraestrutura.

Cidades de porte médio também apresentam esta situação de espalhamento da mancha urbana, uma vez que têm sido nelas evidenciadas as maiores taxas de crescimento urbano nas últimas décadas. A descentralização urbana em direção às áreas periféricas, em muitos casos, é influenciada pela presença de vias de circulação, o que contribui para a maior complexidade da morfologia das cidades. A forma urbana é irregular e complexa, diferenciando-se ao longo do tempo e do espaço, de acordo com as influências do meio em que está inserida, sendo assim impossível adequá-la à regularidade da geometria euclidiana - abordagem comumente utilizada nas análises da forma urbana. É neste contexto que surge a necessidade de novas formas ou ferramentas de análise que permitam maior aproximação ao fenômeno em estudo, no caso para a compreensão das formas urbanas.

A geometria fractal, surge em parte, da incapacidade da geometria clássica ou euclidiana em caracterizar ou medir muitas das formas naturais. Uma linha de costa não é retilínea ou circular, nem uma paisagem pode ser representada por uma função analítica. De maneira semelhante, é difícil ou mesmo impossível descrever flocos de neve, padrões urbanos ou a rede hidrográfica, por meios tradicionais. A dimensão fractal pode, portanto, ser usada principalmente como um índice para medir a complexidade de curvas e superfícies (DE COLA; LAM, 1993), constituindose no grau de complexidade (GOODCHILD; MARK, 1987) e fragmentação (HEROLD, COUCLELIS; CLARKE, 2005) da forma ou objeto em análise. 


\section{ANÁLISE DIRECIONAL DA EXPANSÃO URBANA DE CIDADES DE PORTE MÉDIO: UMA APLICAÇÃO DA DIMENSÃO FRACTAL}

Segundo Tannier e Pumain (2005), referências aos fractais na literatura geográfica são relativamente recentes, tendo surgido a menos de 20 anos e, provavelmente, novos estudos surgirão, mais numerosos e sistemáticos. A principal vantagem da geometria fractal é fornecer um modelo de referência para descrever as formas espaciais criadas pela sociedade que seja mais adaptado que a geometria euclidiana.

A aproximação das formas urbanas à geometria fractal permite maior similaridade entre o modelo em estudo e a forma real. A partir do uso da dimensão fractal (D), como métrica da paisagem, o crescimento urbano pode ser analisado sob o ponto de vista da fragmentação e do preenchimento do espaço, ao longo do tempo.

Para entendermos a dimensão fractal é necessário que nos reportemos à geometria euclidiana, na qual o ponto tem dimensão zero (0); a linha, dimensão um (1); a área, dimensão dois (2); e o volume, dimensão três (3). Na geometria fractal a dimensão possui valores fracionados, o que permite maior exatidão na determinação da dimensão de objetos com formas irregulares (BATTY; LONGLEY, 1994; FRANKHAUSER, 1994).

Ao longo do processo de crescimento urbano a densidade de ocupação e a aleatoriedade quanto à disposição das estruturas influenciam a morfologia urbana. De acordo com Batty, Fotheringham e Longley (1993), a análise morfológica urbana concebe a cidade como ramificações de estruturas em que os espaços entre estas ramificações apresentam reduzida possibilidade de crescimento, acelerando ainda mais a ramificação. $O$ crescimento ao longo de vias de transporte deixa espaços não ocupados, que tendem a diminuir a densidade de ocupação, à medida que aumenta a distância até o centro das cidades.

As ramificações urbanas, segundo Marques e Ferreira (2008), formam uma estrutura com dendritos que crescem em um processo centrífugo, de acordo com a disponibilidade de vias de circulação. Muitas vezes ocorrem limitações neste processo de crescimento, em consequência das características físicas do espaço e pelo próprio perfil econômico destas cidades. Berry (1964) argumenta que dentro da 


\section{ANÁLISE DIRECIONAL DA EXPANSÃO URBANA DE CIDADES DE PORTE MÉDIO: UMA APLICAÇÃO DA DIMENSÃO FRACTAL}

totalidade de ecossistemas mundiais, nos quais o homem é a parte dominante, ele cria para si, muitos ambientes. Estes ambientes não são estudados em sua totalidade pelos geógrafos, somente em seus aspectos espaciais. Nesta perspectiva, o estudo morfológico das cidades encontra sustentação.

Pretende-se com este artigo a identificação e caracterização da forma de cidades de porte médio, por meio da estimativa da dimensão fractal, considerando a densidade de preenchimento a partir do centro urbano, com base em uma série temporal e divisão setorial das áreas urbanas. Propõem-se ainda, verificar a relação entre a dimensão fractal e as características de cada sítio urbano, especificamente a topografia e as atividades de uso do solo praticadas nas áreas próximas às bordas urbanas.

Para atingir estes objetivos foram selecionadas duas cidades de porte médio do estado de São Paulo, Brasil, com morfologias e características físico-geográficas de sítio urbano distintas, mas com populações totais residentes próximas: 376.828 e 425.795 habitantes (SEADE, 2005). As duas cidades corresponderam a São José do Rio Preto (SJRP) e a Jundiaí. Esta última cidade, será denominada neste trabalho de Jundiaí-Várzea Paulista (JVP), pelo fato de constituir um aglomerado urbano ao estar conurbada com a cidade de Várzea Paulista. As áreas de estudo estão localizadas no Planalto Ocidental e no Planalto Atlântico, respectivamente (IPT, 1981), conforme a Figura 1. 


\section{ANÁLISE DIRECIONAL DA EXPANSÃO URBANA DE CIDADES DE PORTE MÉDIO: UMA APLICAÇÃO DA DIMENSÃO FRACTAL}

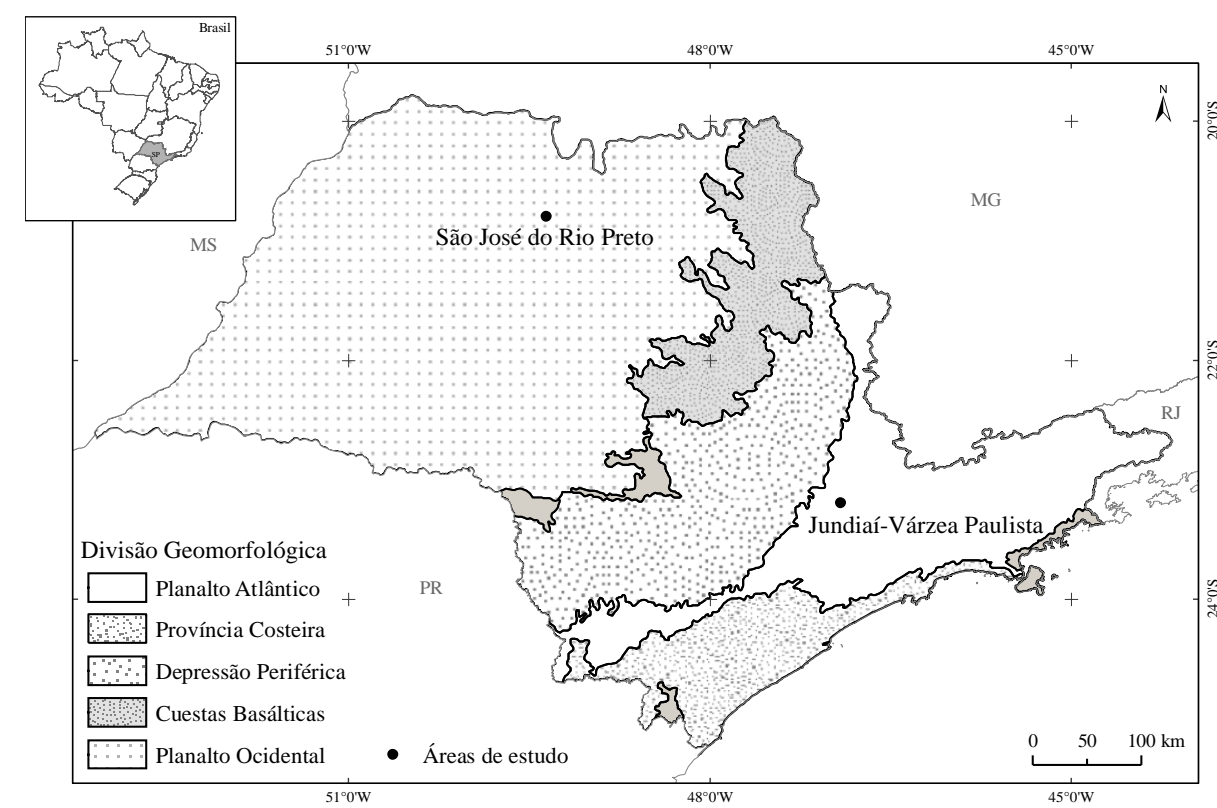

Figura 1: Localização das áreas de estudo no estado de São Paulo considerando a divisão geomorfológica proposta pelo IPT (1981).

A proposta de utilização da estimativa da dimensão fractal como ferramenta de análise espacial além de avaliar o seu desempenho na análise e caracterização do comportamento da morfologia urbana ao longo do tempo, poderá auxiliar em ações de planejamento urbano e territorial quanto ao monitoramento da forma urbana.

\section{MATERIAIS E MÉTODOS}

\subsection{Materiais}

O intervalo de tempo que compõe a série temporal analisada foi escolhido em função da disponibilidade de material cartográfico e de sensoriamento remoto, que compreendessem características de elaboração semelhantes, e também, representassem o panorama histórico de urbanização a partir do qual as duas cidades selecionadas se desenvolveram. Desta forma, o período em estudo compreendeu o intervalo de 1938 a 2005, representado por quatro datas específicas de análise: 1938, 1985, 1995 e 2005.

O material cartográfico e de sensoriamento remoto utilizado para a identificação da expansão urbana das duas cidades foram os seguintes: mapa 
analógico de 1938, elaborado pelo Instituto Geográfico e Geológico, para a cidade de São José do Rio Preto e mapa da área urbana de Jundiaí de 1940, cedido pela Prefeitura Municipal, ambos na escala aproximada de 1:30.000; imagens do satélite LANDSAT TM 5 para os anos de 1985, 1995 e 2005, correspondentes às órbitas/pontos 221/74 e 219/76, obtidas no catálogo de imagens do Instituto Nacional de Pesquisas Espaciais (INPE).

Para a análise dos aspectos físicos da topografia das duas áreas de estudo, foram utilizados os dados ASTER GDEM (2009), cenas: S21W050 para SJRP e S24W047 e S24W048 para o aglomerado JVP. A identificação dos usos do solo no entorno urbano foi realizada em cenas do sensor $\mathrm{HRC}$ do satélite CBERS 2B, obtidas no catálogo do INPE para o ano de 2008, data mais próxima a 2005. Para SJRP, a cena correspondeu à órbita/ponto 158(E)123(4) de 11/04/2008; para JVP foi necessário o uso de quatro cenas, sendo elas: 154(A)/126(2) e 154(A)/126(3) de 19/05/2008 e 154(B)/126(2) e 154(B)/126(3) de 14/06/2008.

As vias de circulação e a rede hidrográfica que compõem a base cartográfica das áreas de estudo foram obtidas a partir de mapas do Departamento de Estradas e Rodagem do estado de São Paulo (DER) em escala 1:250.000. Todas as etapas de processamento digital das imagens e obtenção dos resultados foi desenvolvida nos softwares Idrisi Taiga e ArcGIS 9.3.

\subsection{Processamento digital e identificação da expansão urbana}

Os materiais cartográficos e de sensoriamento remoto foram registrados a partir da imagem LADNSAT TM 5 de 2005, mantendo-se um erro padrão inferior a um pixel, conforme a resolução espacial de $30 \mathrm{~m}$, adotada para a pesquisa. Após o registro, as imagens foram recortadas com base na extensão territorial de cada município e definidas as composições coloridas para a identificação da expansão urbana nas quatro datas de análise. As composições coloridas consideradas adequadas para esta etapa foram: RGB 357; RGB 347 e RGB 741.

Em seguida, as manchas urbanas para os anos de 1938, 1985, 1995 e 2005 foram vetorizadas em tela, em escala fixa 1:50.000, sendo identificada, nas duas 
cidades, somente a área urbana consolidada ou efetivamente urbanizada nestas datas.

\subsection{Caracterização dos aspectos físicos e antrópicos}

A partir do modelo digital de elevação (MDE) dos dois municípios, com base nos dados GDEM, foram elaboradas as representações cartográficas para as características topográficas de cada área. Para esta etapa a legenda foi estruturada de forma a permitir a comparação das características de relevo presentes nas duas áreas de estudo.

A caracterização do uso e ocupação presentes na borda urbana das cidades foi realizada por meio da interpretação e vetorização em tela das imagens HRC do satélite CBERS 2B. Uma zona buffer de $1 \mathrm{~km}$ foi traçada a partir da área urbanizada no ano de 2005, em cada cidade. O uso do solo foi mapeado somente nesta faixa. Esta delimitação relacionou-se com o objetivo da pesquisa, quanto à análise da relação entre $\mathrm{D}$ e o uso do solo na borda urbana o que pode influenciar no grau de fragmentação. Foram pré-definidas e identificadas cinco classes de uso para esta etapa: vegetação arbórea, cultivo, áreas industriais, áreas urbanizadas, vegetação rasteira. No aglomerado JVP foi identificada também a classe água, em consequência de um reservatório em sua borda urbana.

O uso e ocupação do entorno de cada área urbana foi mapeado com base nesta chave de interpretação. Nesta etapa, as informações espaciais disponibilizadas pelo Google Earth constituíram-se também em suporte na interpretação e vetorização das classes de uso.

\subsection{Estimativa da dimensão fractal para as formas urbanas}

A dimensão fractal (D) foi calculada segundo o método da densidade de ocupação ou de preenchimento urbano, utilizado por Frankhauser (1994; 1998), Batty e Longley (1994), Longley e Mesev (2002) e Marques e Ferreira (2006; 2008). Este método considera a diminuição da densidade de preenchimento urbano com 0 afastamento do centro urbano. Para o cálculo da estimativa da dimensão fractal pelo 


\section{ANÁLISE DIRECIONAL DA EXPANSÃO URBANA DE CIDADES DE PORTE MÉDIO: UMA APLICAÇÃO DA DIMENSÃO FRACTAL}

método proposto, inicialmente os arquivos vetoriais referentes às áreas urbanizadas em cada data foram transformados em arquivos matriciais, com resolução espacial de $30 \mathrm{~m}$. Em seguida, procedeu-se ao posicionamento do centro médio de cada cidade, definidos segundo os mapas de 1938 e 1940, por serem estes mais próximos das datas de fundação ou início da formação urbana.

A partir dos centros médios urbanos foram interpoladas superfícies de isodistâncias, reclassificadas em círculos concêntricos, com intervalos de $500 \mathrm{~m}$. Estes círculos foram sobrepostos às manchas urbanas de cada data, e estimados os valores de área ocupada em cada círculo de distância, até o centro médio urbano.

Os valores de área urbana ocupada e a área ocupada total de cada círculo concêntrico foram utilizados como referência para o cálculo da densidade de ocupação, que faz parte da estimativa de D. O cálculo da densidade de ocupação urbana foi realizado a partir da seguinte relação:

$$
\rho(R)=\frac{N(R)}{A(r)}
$$

onde $\rho(R)$ é a densidade de preenchimento da área urbana a uma distância $R$ em relação ao centro urbano; $N(R)$ é a área urbana ocupada em $R ; A(r)$ refere-se à área total ocupada em R. Os valores de área, densidade de ocupação e distâncias a partir do centro da cidade foram empregados no cálculo da $D$, com base na relação:

$$
D(R)=2+\frac{\log \rho(R)}{\log R}
$$

onde $D(R)$ é a dimensão fractal de cada faixa $R$ medida a partir do centro urbano. Os valores de $D$ variam entre 1 e $2 ; D=2$ quando o preenchimento urbano é total na referida faixa $R ; 1<D<2$, o preenchimento é incompleto, apresentando diferentes graus de fragmentação. Os valores de $\mathrm{D}$ podem variar com a distância em relação ao centro; o que representa a maior ou menor fragmentação em direção às áreas periféricas das manchas urbanas. 


\section{ANÁLISE DIRECIONAL DA EXPANSÃO URBANA DE CIDADES DE PORTE MÉDIO: UMA APLICAÇÃO DA DIMENSÃO FRACTAL}

Para a melhor compreensão do detalhamento da fragmentação urbana propôs-se a análise setorial de $\mathrm{D}$, com base na metodologia utilizada por Marques e Ferreira (2008) no estudo da região metropolitana de São Paulo. Os círculos concêntricos com intervalos de $500 \mathrm{~m}$, representando o distanciamento em relação ao centro urbano, foram subdivididos em oito setores direcionais de $45^{\circ}$, mantendose as distâncias intervalares de $500 \mathrm{~m}$, a partir do centro urbano: ENE; ESE; NNE; NNO; ONO; OSO; SSE; SSO.

A intersecção entre cada um destes setores direcionais de $45^{\circ} \mathrm{com}$ as áreas urbanas para cada uma das datas de análise forneceu os valores de área urbana ocupada em cada setor, ao longo da série temporal. Em seguida, foram calculados os valores de $\mathrm{D}$ de acordo com o afastamento do centro urbano, em cada setor direcional, nas quatro datas de análise.

\subsection{Análise espacial}

Considerando-se que $\mathrm{D}$ representa o padrão espaço-tempo da evolução da fragmentação urbana, a análise setorial de sua variação temporal pode ser estimada por meio dos mínimos quadrados entre as datas, a partir da seguinte relação:

$$
D(\theta, t)=\Sigma\left(D_{t}-D_{t-1}\right)^{2}
$$

onde $\mathrm{D}(\theta, t)$ corresponde aos valores de $\mathrm{D}$, em cada setor direcional, nas datas 1938, 1985, 1995 e 2005.

A morfologia de cada sítio urbano foi analisada de maneira quantitativa e qualitativa, por setor direcional, no período 1938-2005. Nesta análise foram considerados três fatores espaciais: a) as características topográficas do sítio urbano; b) o uso do solo na área de entorno da cidade; e c) a dimensão fractal (D) da área urbanizada total e dos setores direcionais. 


\section{ANÁLISE DIRECIONAL DA EXPANSÃO URBANA DE CIDADES DE PORTE MÉDIO: UMA APLICAÇÃO DA DIMENSÃO FRACTAL}

\section{RESULTADOS E DISCUSSÃO}

A formação e morfologia das cidades do interior do estado de São Paulo foram influenciadas pelo desenho das vias férreas (SERRA, 1987). O processo de formação das duas áreas de estudo confirma esta relação entre cidade e ferrovia. Enquanto SJRP, município autônomo desde 1894, transformou-se em pólo comercial e regional, concentrando a produção de mercadorias devido a sua posição como terminal de linha férrea; Jundiaí, emancipado em 1865, tornou-se grande centro produtor de café em decorrência de sua posição estratégica como entroncamento ferroviário e a chegada de imigrantes, que substituíram a mão-deobra escrava no século XIX. Atualmente, SJRP constitui-se em pólo de desenvolvimento regional e Jundiaí atraiu muitas indústrias tornando-se um grande parque industrial (SEADE, 2011).

A identificação das áreas urbanas nas quatro datas da série temporal revelou que, embora as suas áreas sejam semelhantes, as formas urbanas são bastante distintas, fato que pode ser verificado nas Figuras 2 e 3 . Enquanto a forma urbana de SJRP tende à circularidade, JVP apresenta maior tendência ao alongamento na direção SE-NO.

As representações cartográficas da expansão urbana das cidades revelam também os possíveis eixos de crescimento, em geral, acompanhando as vias de circulação (Figura 2). Esta característica é mais intensa no aglomerado JVP, por influência das rodovias Anhanguera (SP 330) e Bandeirantes (SP 348), que seccionam esta área urbana e conectam o interior paulista à região metropolitana de São Paulo. A própria localização do aglomerado JVP nas proximidades da região metropolitana de São Paulo contribuiu para a atual configuração de sua mancha urbana. 

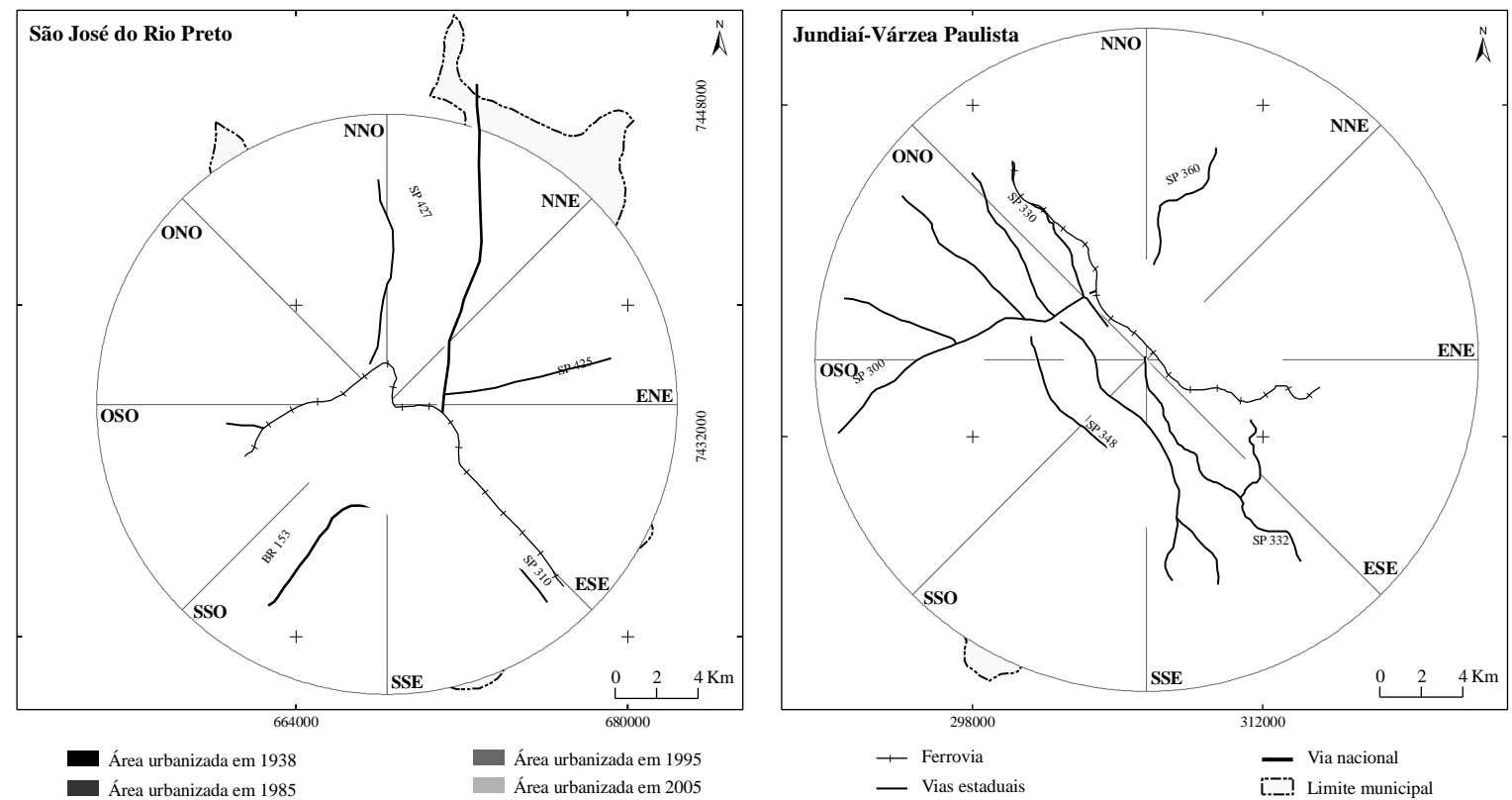

Figura 2: Representações da expansão urbana no período entre 1938 e 2005, com a sobreposição das principais vias de circulação e dos setores direcionais propostos em cada cidade.

A dinâmica morfológica das manchas urbanas destas cidades também se reflete na evolução de suas características populacionais ao longo do período (Figura 3). Ambas as cidades apontaram um grande crescimento populacional entre 1940 e 1985, período que caracterizou importantes transformações econômicas no cenário nacional e principalmente no estado de São Paulo (ver SINGER, 1977; SEADE, 1992; FURTADO, 1999).

$\mathrm{Na}$ Figura 3 pode ser verificado o contínuo crescimento populacional observado no período recente, mas de modo mais lento. Estas cidades apresentaram elevadas taxas de urbanização, conforme dados da SEADE em 2010 - JVP (96,66\%) e SJRP (93,91\%). De acordo com a UN-HABITAT (2008), este crescimento mais lento da população urbana é uma tendência verificada em escala mundial. 


\section{ANÁLISE DIRECIONAL DA EXPANSÃO URBANA DE CIDADES DE PORTE MÉDIO: UMA APLICAÇÃO DA DIMENSÃO FRACTAL}
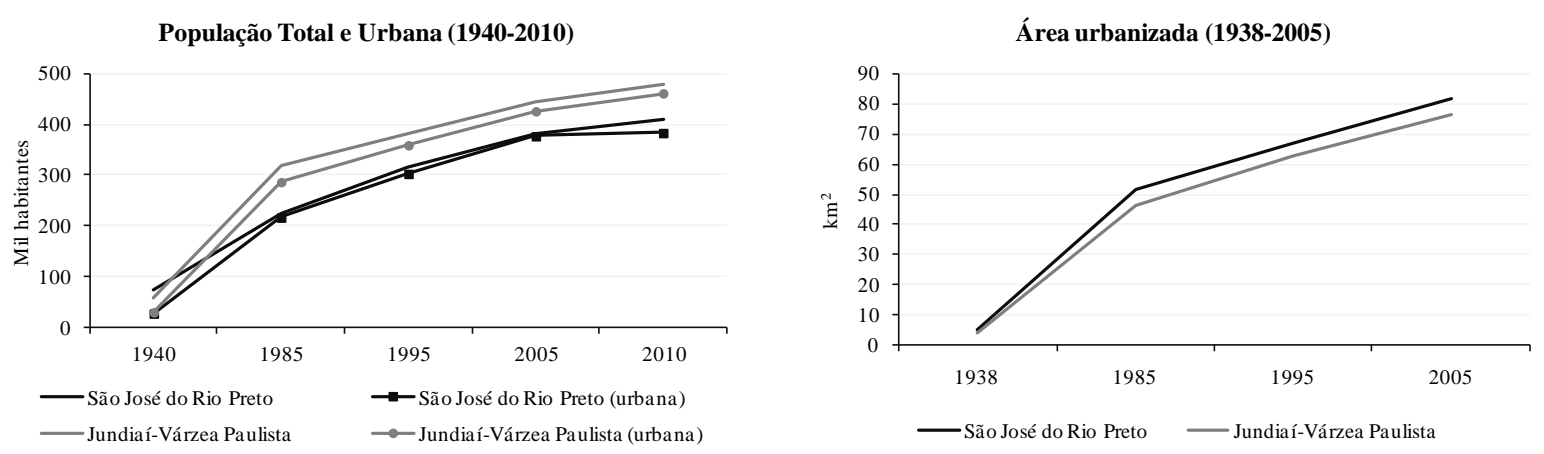

Figura 3: Evolução da população total e urbana e do tamanho da área urbanizada de SJRP e JVP, entre 1940 e 2010.

O comportamento evolutivo das cidades nos setores direcionais de $45^{\circ}$, sobrepostos às manchas urbanas (Figura 2), mostra o maior equilíbrio na distribuição espacial da mancha urbana em SJRP, em face de suas características morfológicas (Figura 4). Já em JVP alguns setores direcionais se destacam quanto à concentração de áreas ocupadas, como, por exemplo, os setores ONO, ESE e SSE.
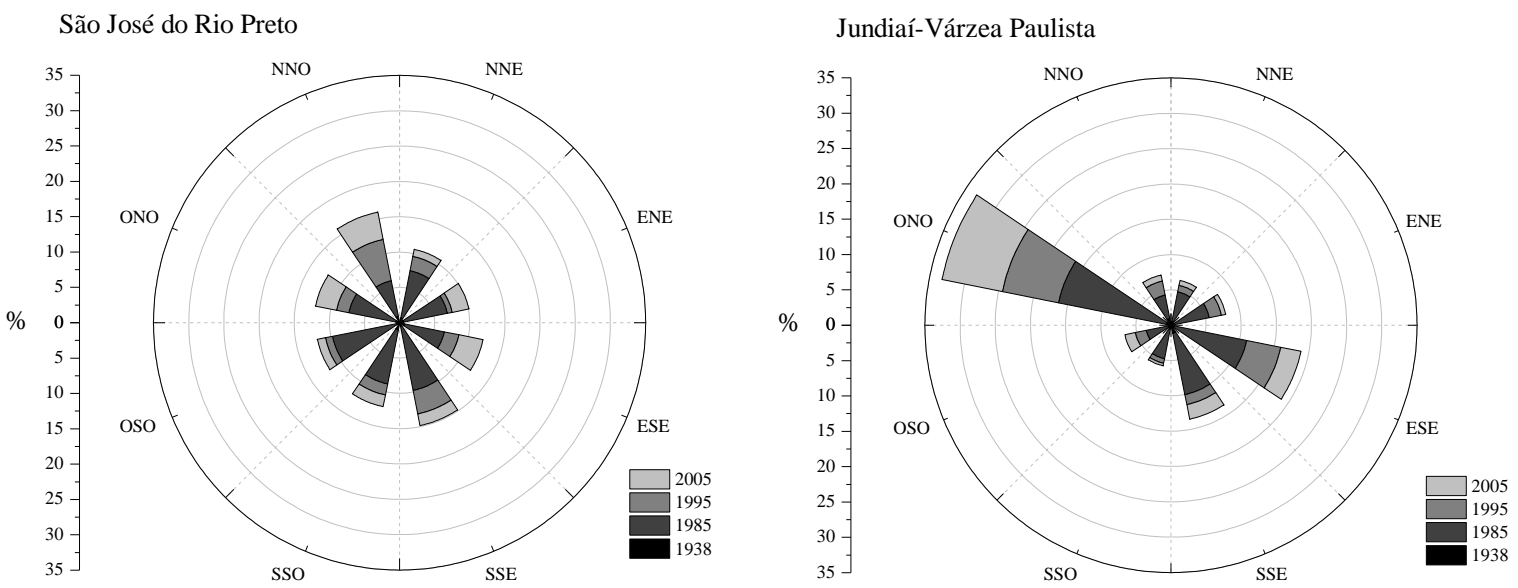

Figura 4: Distribuição da proporção de áreas urbanizadas por setor direcional e por ano, para as cidades de SJRP e JVP.

Esta distribuição desigual de áreas urbanizadas nos setores direcionais é resultado, principalmente, da influência do sistema viário e, também, dos aspectos físico-geográficos que caracterizam cada sítio urbano. Este fato pode ser verificado a partir das representações topográficas das áreas de estudo (Figura 5). 


\section{ANÁLISE DIRECIONAL DA EXPANSÃO URBANA DE CIDADES DE PORTE MÉDIO: UMA APLICAÇÃO DA DIMENSÃO FRACTAL}
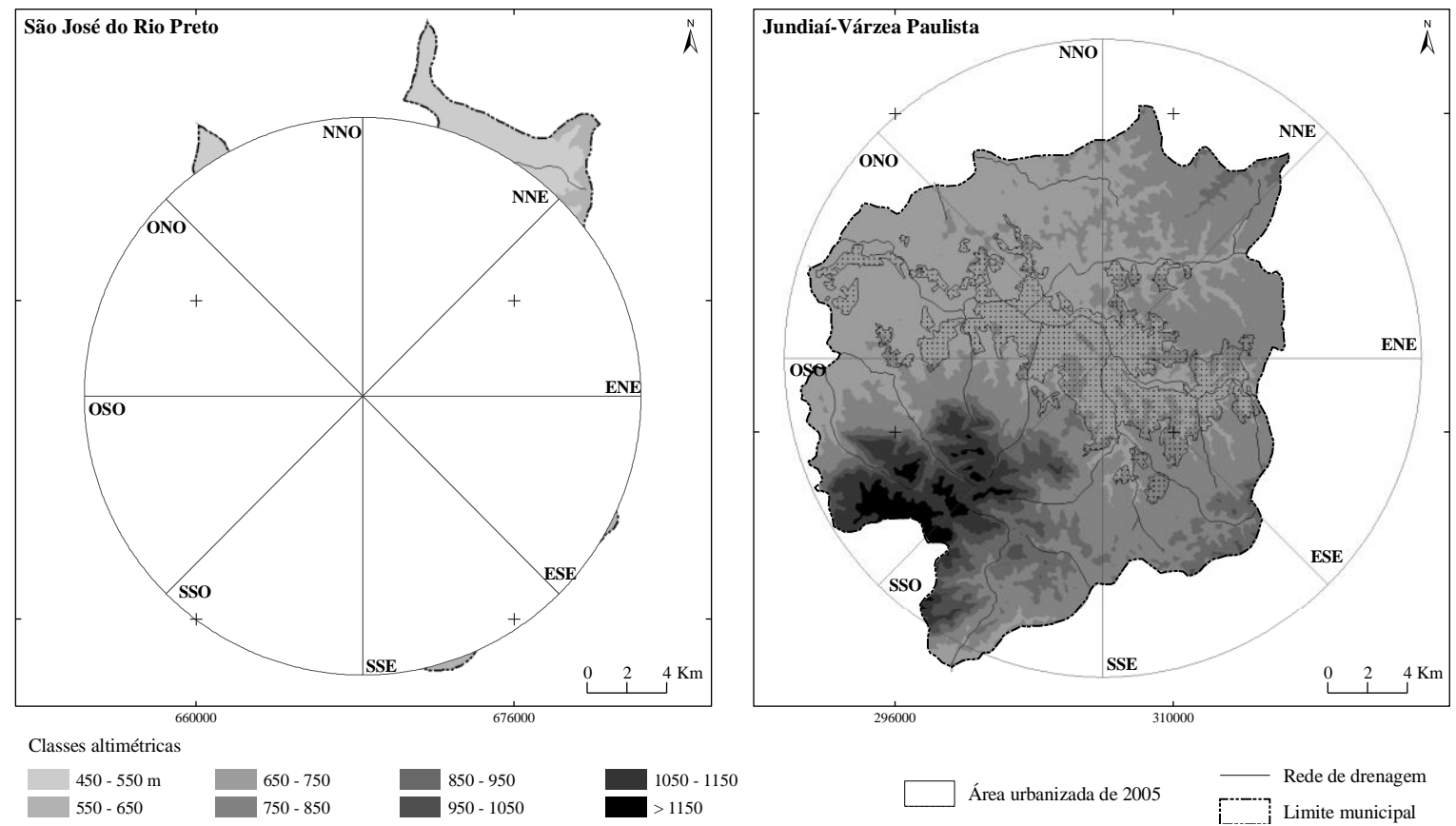

lasses altimétricas

$\begin{array}{llll}450-550 \mathrm{~m} & 650-750 & 850-950 & 1050-1150 \\ 550-650 & 750-850 & 950-1050 & 1150\end{array}$ Figura 5. Representações da topografia das áreas de estudo a partir do modelo digital de elevação.

Em SJRP predominam baixas altitudes, de até $600 \mathrm{~m}$, caracterizando relevo plano de baixa amplitude, levemente ondulado; em JVP ocorre maior amplitude altimétrica, entre 660 até $1.280 \mathrm{~m}$. Analisando-se os fatores topográficos nota-se que a expansão de SJRP não encontrou grandes impedâncias topográficas para seu crescimento; em JVP, as maiores impedâncias topográficas, situadas nos setores SSO e OSO, principalmente, representaram limitações à expansão urbana no mesmo período. Estas áreas de maior altitude, em JVP, correspondem á Serra do Japi, que abriga remanescentes da Mata Atlântica, constituindo-se em uma Área de Preservação Ambiental (APA), conforme Mattos e Ferreira (2007).

A forma urbana é influenciada significativamente pela sua localização, fatores físico-geográficos (relevo, hidrografia) o que contribui para a existência de vazios urbanos, áreas verdes, limites, contornos, cotas das construções, percursos, desenhos dos caminhos entre outros. O avanço tecnológico permitiu a modificação da forma, embora o traçado geral das cidades já esteja definido a partir de sua ocupação inicial (SERRA, 1987). 


\section{ANÁLISE DIRECIONAL DA EXPANSÃO URBANA DE CIDADES DE PORTE MÉDIO: UMA APLICAÇÃO DA DIMENSÃO FRACTAL}

Além dos aspectos de topografia, o uso e ocupação do solo nas proximidades das bordas urbanas podem ter alguma relação com a morfologia urbana, influenciando no grau de fragmentação urbana. A quantificação do uso e ocupação do solo por categoria é apresentada na Figura 6 e nas Tabelas 1 e 2.

Conforme a Figura 6, as áreas de vegetação rasteira ou áreas ainda não urbanizadas são predominantes (pouco superior a $30 \%$ ) na faixa de $1 \mathrm{~km}$ para as duas cidades. As diferenças de uso da borda entre as cidades aparecem relacionadas às áreas de cultivo, mais representativas em SJRP, o que caracteriza um perfil agrícola $(11,91 \%$ de áreas de cultivo contra 3,22\% em JVP). Observa-se em JVP o predomínio de áreas de vegetação arbórea (matas e silvicultura) - de $15,68 \%$ enquanto esta classe representa 3,40\% em SJRP. A menor diferença de usos ocorre para as áreas urbanizadas que correspondem aos fragmentos urbanos dispersos ao longo de sua borda. No entanto, estes fragmentos dispersos ainda representam maior número em JVP.

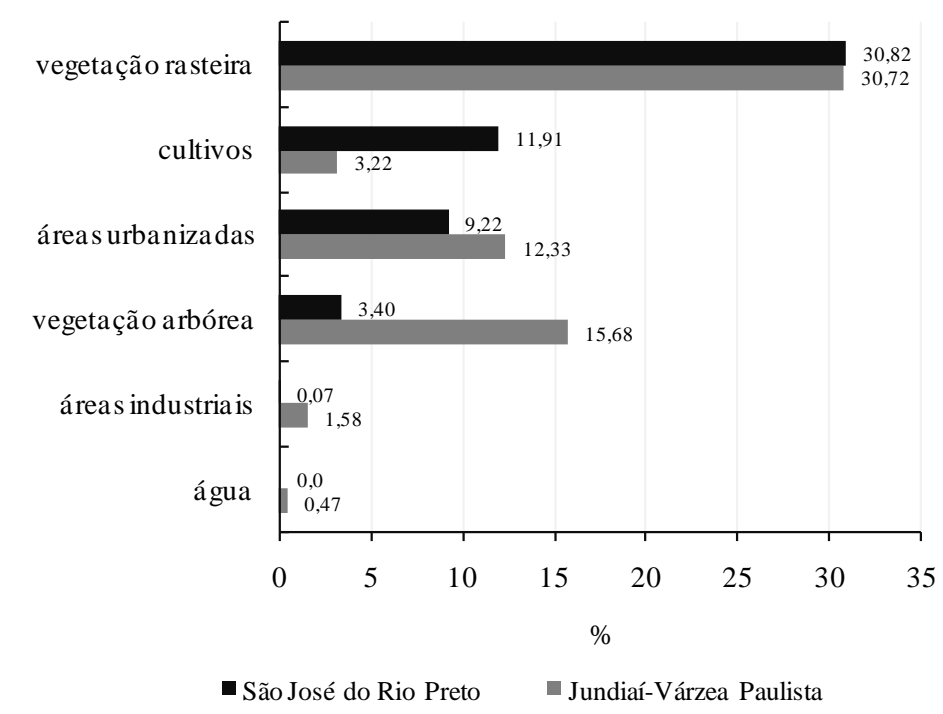

Figura 6: Distribuição do uso e ocupação do solo, em uma faixa de $1 \mathrm{~km}$ no entorno das cidades.

Embora não seja possível se comparar a área ocupada pela faixa de $1 \mathrm{~km}$, a partir dos setores direcionais, uma vez que as manchas urbanas são irregulares fato que confere diferenças para esta faixa, em cada setor, é coerente se 


\section{ANÁLISE DIRECIONAL DA EXPANSÃO URBANA DE CIDADES DE PORTE MÉDIO: UMA APLICAÇÃO DA DIMENSÃO FRACTAL}

estabelecer algumas considerações quanto aos usos da borda entre os setores, de acordo com as informações das Tabelas 1 e 2.

Em SJRP pode-se verificar que o uso do solo na borda é mais diversificado entre os setores, à exceção da área de uso industrial. Contudo, é evidente em ambas as cidades a maior concentração de áreas urbanizadas associadas com áreas de vegetação rasteira ou ainda não urbanizadas, que correspondem aos setores com maior fragmentação de borda (ONO em JVP e SSE e ESE em SJRP). Isto indica a baixa densidade de ocupação na borda, uma das características do processo de dispersão urbana ou urban sprawl (EWING, 1994, TORRENS; ALBERTI, 2000) e ainda pode estar relacionado com a própria especulação imobiliária.

Tabela 1: Distribuição do percentual de uso do solo por categoria na faixa de $1 \mathrm{~km}$ no entorno de São José do Rio Preto.

\begin{tabular}{|c|c|c|c|c|c|}
\hline & $\begin{array}{c}\text { Áreas } \\
\text { Urbanizadas } \\
(\%)\end{array}$ & $\begin{array}{c}\text { Áreas } \\
\text { industriais (\%) }\end{array}$ & Cultivos (\%) & $\begin{array}{l}\text { Vegetação } \\
\text { rasteira (\%) }\end{array}$ & $\begin{array}{l}\text { Vegetação } \\
\text { arbórea (\%) }\end{array}$ \\
\hline ENE & 10,32 & 0 & 20,48 & 9,37 & 12,30 \\
\hline ESE & 18,26 & 0 & 18,18 & 18,60 & 6,69 \\
\hline NNE & 10,00 & 0 & 4,38 & 13,96 & 21,08 \\
\hline NNO & 5,34 & 0 & 5,54 & 13,90 & 11,74 \\
\hline ONO & 4,94 & 0 & 10,01 & 10,49 & 19,52 \\
\hline Oso & 6,16 & 90,70 & 4,15 & 9,01 & 9,50 \\
\hline SSE & 30,46 & 9,30 & 32,22 & 14,14 & 10,01 \\
\hline SSO & 14,52 & 0 & 5,04 & 10,53 & 9,16 \\
\hline Total & 100 & 100 & 100 & 100 & 100 \\
\hline
\end{tabular}

A caracterização das cidades quanto à área, população, aspectos físicos e de uso e ocupação da borda urbana, são elementos importantes. No entanto, relações ainda mais consistentes podem ser obtidas com a análise do grau de fragmentação da forma urbana, estimado pela dimensão fractal (D). 


\section{ANÁLISE DIRECIONAL DA EXPANSÃO URBANA DE CIDADES DE PORTE MÉDIO: UMA APLICAÇÃO DA DIMENSÃO FRACTAL}

Tabela 2: Distribuição do percentual de uso do solo por categoria na faixa de $1 \mathrm{~km}$ no entorno de Jundiaí-Várzea Paulista.

\begin{tabular}{llllll}
\hline & $\begin{array}{c}\text { Áreas } \\
\text { Urbanizadas } \\
(\%)\end{array}$ & $\begin{array}{c}\text { Áreas } \\
\text { industriais (\%) }\end{array}$ & \multicolumn{1}{c}{ Cultivos (\%) } & $\begin{array}{c}\text { Vegetação } \\
\text { rasteira (\%) }\end{array}$ & $\begin{array}{c}\text { Vegetação } \\
\text { arbórea (\%) }\end{array}$ \\
\hline ENE & 14,34 & 0 & 11,25 & 6,53 & 13,70 \\
ESE & 18,47 & 5,18 & 0 & 7,40 & 10,88 \\
NNE & 6,76 & 0 & 6,30 & 8,72 & 10,16 \\
NNO & 12,40 & 0 & 13,18 & 11,09 & 10,73 \\
ONO & 22,84 & 88,02 & 67,63 & 42,45 & 17,97 \\
OSO & 8,23 & 4,89 & 1,64 & 11,36 & 10,72 \\
SSE & 15,20 & 1,91 & 0 & 8,15 & 14,81 \\
SSO & 1,76 & 0 & 0 & 4,30 & 11,03 \\
\hline Total & 100 & 100 & 100 & 100 & 100 \\
\hline
\end{tabular}

A análise da forma urbana com base apenas na extensão em área ocupada, não é suficiente para compreender a morfologia das cidades, uma vez que esta medida não é representativa do desenho assumido por elas ao longo do tempo. Embora SJRP e JVP tenham apresentado semelhanças em área ocupada, suas diferenças morfológicas podem ser confirmadas nas respectivas assinaturas fractais no tempo, a partir das quatro datas de análise (Figura 7).

As assinaturas fractais indicam o maior preenchimento urbano na parte central das duas cidades (menores distâncias do centro urbano). Além disso, este preenchimento tende a se intensificar ao longo do tempo. Por exemplo, a uma distância de até $5 \mathrm{~km}$ do centro urbano, SJRP tem dimensão fractal elevada (valores de D próximos a 2,0); a cidade de JVP apresenta valores de D menores, sobretudo após a distância de $3 \mathrm{~km}$ do centro. Estas rupturas podem ser observadas nos gráficos da Figura 7.

A diminuição de $D$ com o afastamento do centro urbano que se deve ao aumento da fragmentação em direção às bordas, é mais acentuada em JVP. Além disto, os valores de D desta cidade são menores que os calculados para SJRP, apontando, portanto, maior fragmentação de toda a sua mancha urbana ao longo do período. 


\section{ANÁLISE DIRECIONAL DA EXPANSÃO URBANA DE CIDADES DE PORTE MÉDIO: UMA APLICAÇÃO DA DIMENSÃO FRACTAL}
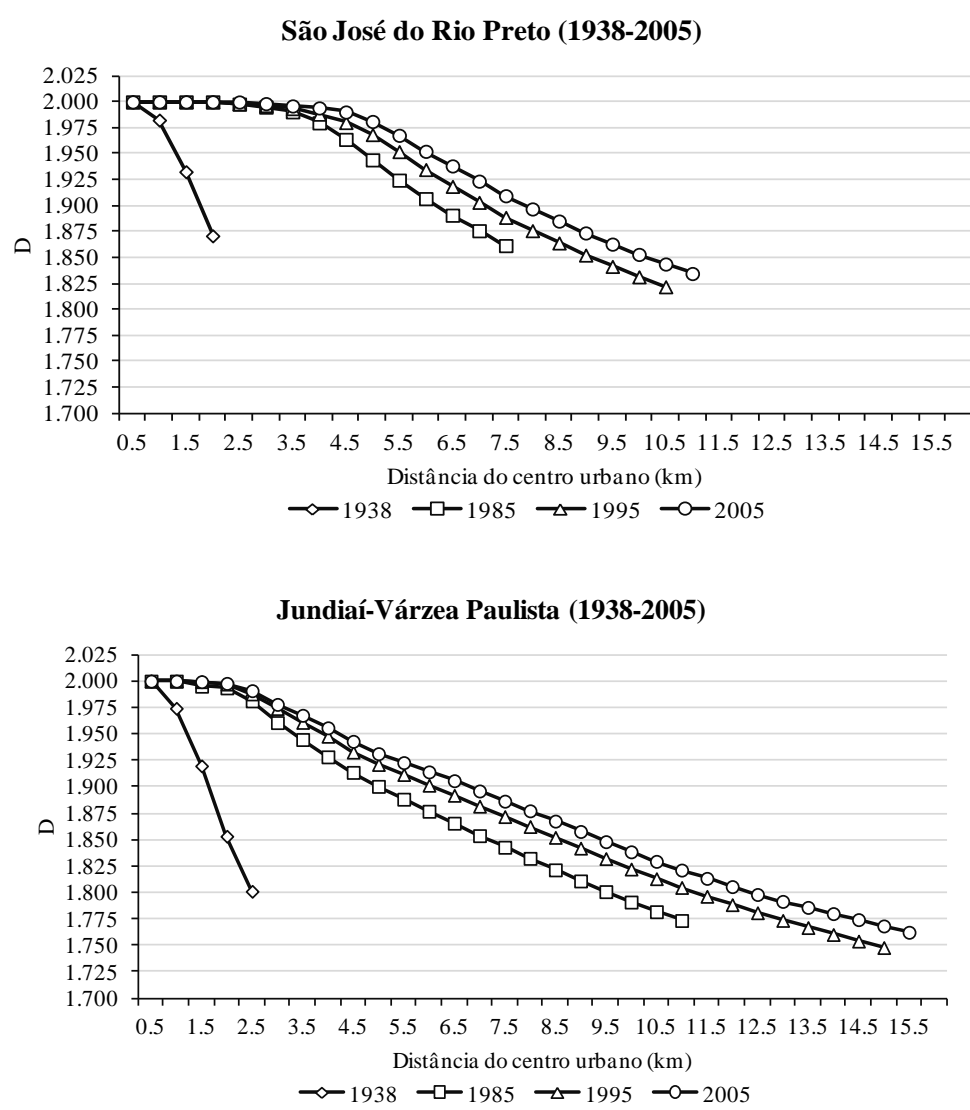

Figura 7: Assinaturas fractais das áreas urbanas para as quatro datas de análise.

De forma semelhante, Marques e Ferreira (2006) também verificaram o maior preenchimento urbano temporal da região metropolitana de São Paulo, utilizando a mesma metodologia. De acordo com Batty e Longley (1994), a maior densidade de ocupação nas áreas centrais e sua diminuição em direção às áreas periféricas têm importância no crescimento das cidades, pois as áreas periféricas tendem a homogeneizar sua densidade de ocupação antes de se espalhar para novas áreas. Para Torrens e Alberti (2000), metodologias com base em fractais são boas ferramentas para caracterizar a habilidade de preenchimento das cidades e oferecem meios que permitem medir a extensão de fenômenos como a expansão urbana em níveis entre dimensões.

As assinaturas fractais estimadas a partir dos setores direcionais oferecem mais informações sobre a fragmentação das formas urbanas, pois permitem 


\section{ANÁLISE DIRECIONAL DA EXPANSÃO URBANA DE CIDADES DE PORTE MÉDIO: UMA APLICAÇÃO DA DIMENSÃO FRACTAL}

identificar vetores de maior preenchimento urbano ou maior irregularidade da forma urbana, bem como, relacionar a fragmentação urbana a elementos que exerçam influência em tais configurações morfológicas. As assinaturas fractais setoriais, das duas áreas urbanas, em cada data de análise, são apresentadas nas Figuras 8 e 9.

Enquanto as assinaturas fractais dos setores direcionais de SJRP apresentam maior regularidade ao longo do tempo, com valores de $D$ elevados na porção central e decrescentes em direção às bordas, os setores de JVP mostram maiores oscilações, com maior fragmentação em direção à borda, sobretudo nos setores ESE, NNE e OSO. A partir das assinaturas setoriais é possível se notar a existência de maiores influências, ou até de impedâncias espaciais ao crescimento urbano de JVP.
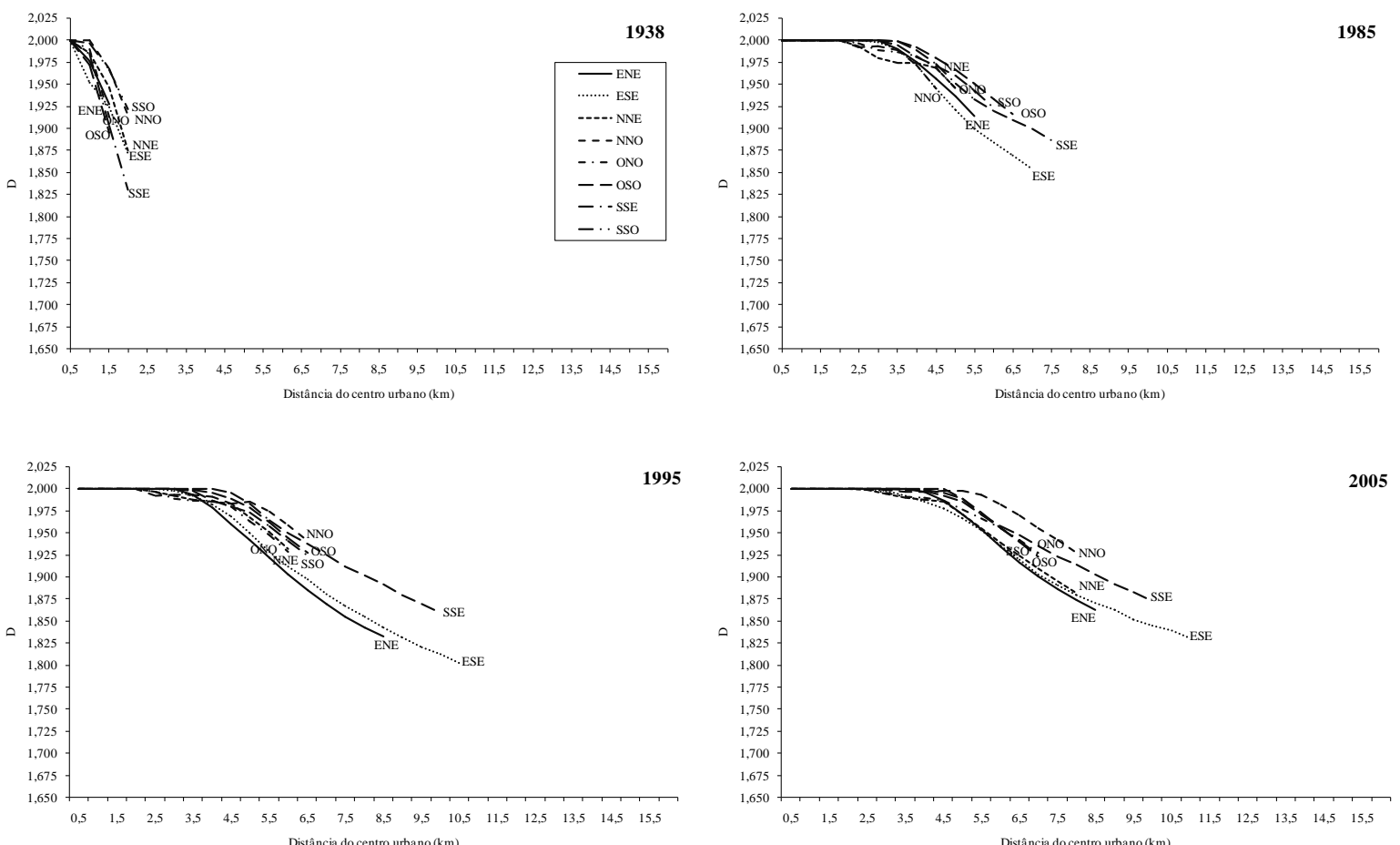

Figura 8: Assinaturas fractais setoriais para São José do Rio Preto no período 1938-2005. 

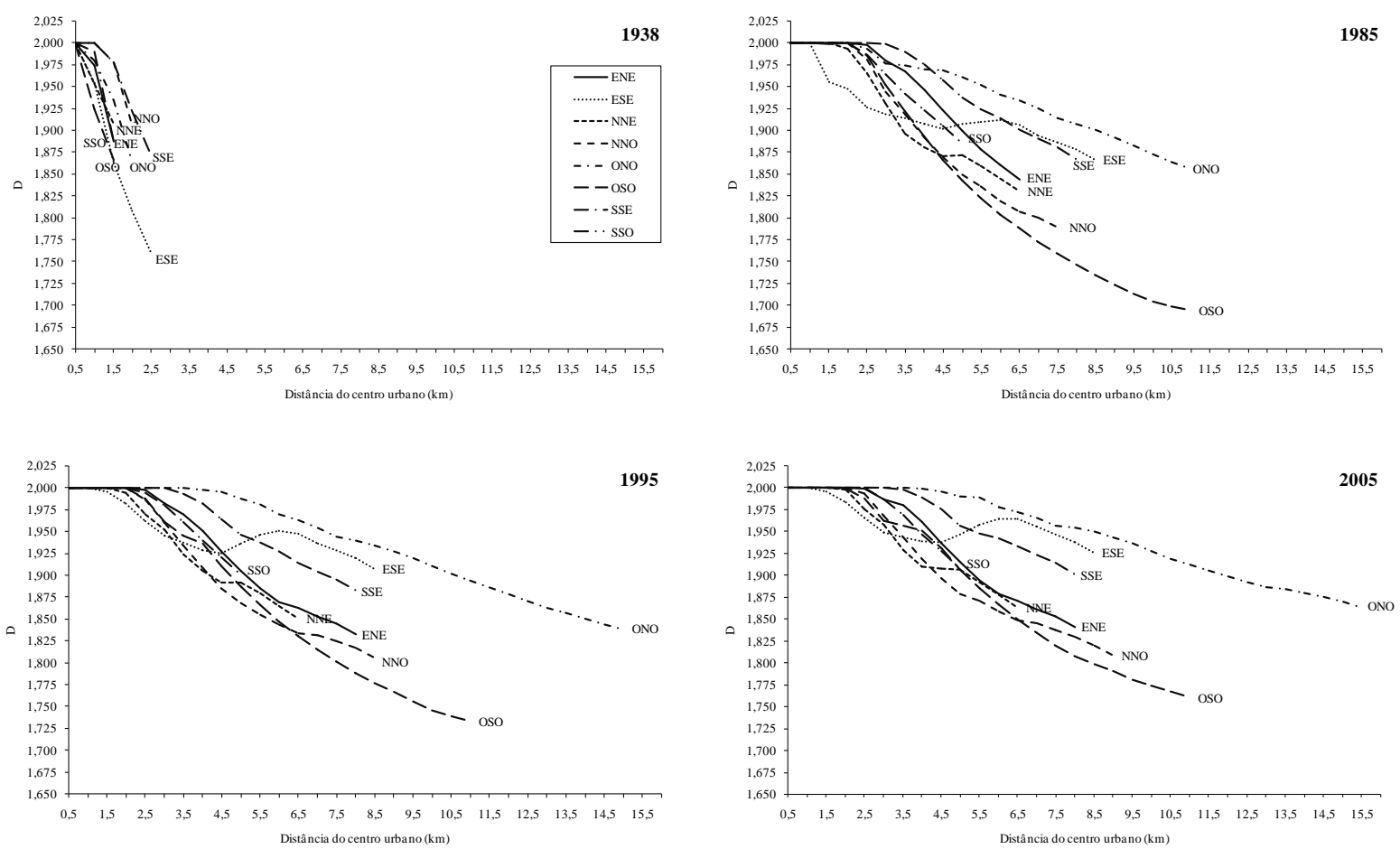

Figura 9: Assinaturas fractais setoriais para Jundiaí-Várzea Paulista no período 1938-2005.

Associando-se as assinaturas fractais às características de relevo e ao uso do solo da borda para as duas cidades, verifica-se a maior participação das características físicas na configuração de JVP, uma vez que nos setores SSO, SSE e ESE (maiores altitudes), a mancha urbana é mais compacta, ou seja, o preenchimento urbano é mais homogêneo em vista dos maiores valores de $D$ até mesmo na borda urbana (Figura 10). Isto ocorre também no setor OSO, embora sua caracterização seja influenciada pela linha de limite dos setores direcionais (posição fixa de $45^{\circ}$ ). A maior compactação urbana nestes setores decorre dos limites mais rígidos impostos pela Serra do Japi. 


\section{ANÁLISE DIRECIONAL DA EXPANSÃO URBANA DE CIDADES DE PORTE MÉDIO: UMA APLICAÇÃO DA DIMENSÃO FRACTAL}

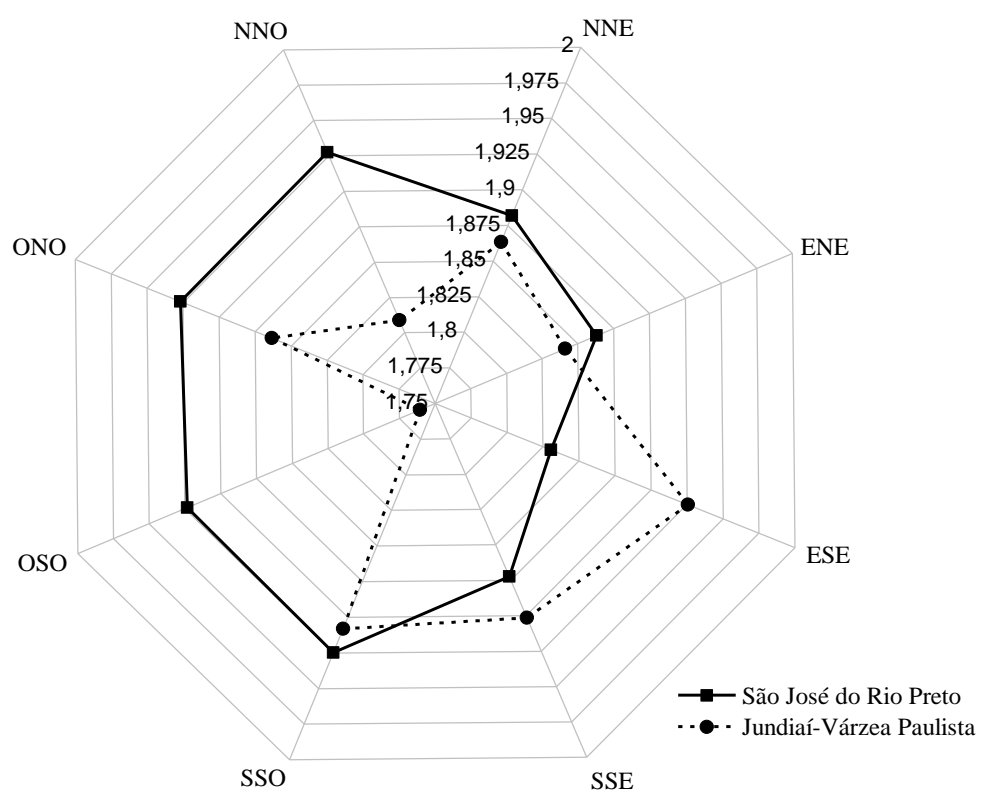

Figura 10: Distribuição dos valores da dimensão fractal (D) da borda urbana, segundo setores direcionais urbanos de São José do Rio Preto e Jundiaí-Várzea Paulista, em 2005.

Em SJRP, a topografia de menor amplitude altimétrica não impediu o crescimento urbano. A fragmentação de borda apresenta maior homogeneidade entre os setores (Figura 10), embora seja visível a influência relativa das vias de circulação, nos setores ESE e SSE. A maior fragmentação urbana de JVP pode estar associada aos usos do entorno urbano, onde há a maior concentração de condomínios e chácaras (uso correspondente a áreas urbanizadas, nos setores NNO, NNE, ONO e ENE); que apresentam maior variação nos valores de D. Isto pode estar relacionado também com a proximidade das regiões metropolitanas de São Paulo e de Campinas.

De modo geral, é possível se afirmar que os usos do solo na borda urbana não representam impedimentos significativos para a expansão urbana. Nas duas cidades predominam áreas com vegetação rasteira ou ainda não urbanizadas, as quais correspondem a áreas desocupadas e que tendem a ser urbanizadas. Porém, as áreas com vegetação arbórea podem representar maior resistência, em vista da legislação ambiental que define sua preservação e, principalmente, a importância que representam para a qualidade de vida urbana. 


\section{ANÁLISE DIRECIONAL DA EXPANSÃO URBANA DE CIDADES DE PORTE MÉDIO: UMA APLICAÇÃO DA DIMENSÃO FRACTAL}

A variabilidade da fragmentação urbana, indicada pelos valores de $D$, para os setores (Figura 11), foi calculada a partir do método dos mínimos quadrados, para os valores médios de $D$ e para o último círculo, ou seja, os valores de $D$ da última distância atingida pela mancha urbana em cada setor direcional.
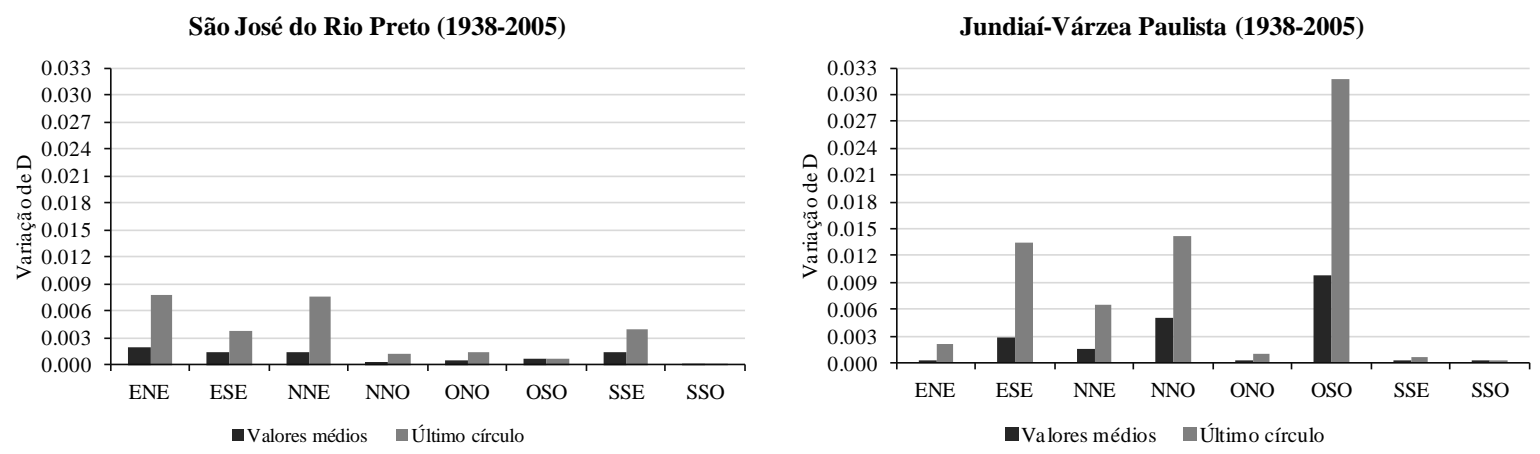

Figura 11: Variação temporal dos valores de D para cada setor direcional nas duas cidades (19382005).

A maior variação no período, tanto para os valores médios como para os valores do último círculo, ocorreu para JVP, sobretudo nos setores OSO, NNO e ESE (Figura 9). Esta maior variação não está relacionada ao aumento de área ocupada nos referidos setores (Figura 4), mas sim, com a forma de preenchimento urbano (principalmente no setor ESE) e com a fragmentação de borda.

Em SJRP, os setores com maior variabilidade corresponderam à totalidade leste da mancha urbana (ENE, ESE, NNE e SSE), o que pode estar relacionado com a presença dos vales dos rios que cortam a cidade e conferem maior complexidade à forma urbana nesta porção territorial.

\section{CONSIDERAÇÕES FINAIS}

As duas cidades de porte médio estudadas, embora possuam população e áreas urbanizadas similares, apresentaram formas urbanas bem distintas. A análise setorial realizada com base no método da dimensão fractal pelo preenchimento urbano permitiu caracterizar as formas com maior detalhamento. Os valores de D para as cidades mostraram que em ambas há o maior preenchimento nas áreas 


\section{ANÁLISE DIRECIONAL DA EXPANSÃO URBANA DE CIDADES DE PORTE MÉDIO: UMA APLICAÇÃO DA DIMENSÃO FRACTAL}

centrais e o aumento da fragmentação com o afastamento do centro urbano. A fragmentação da forma urbana se mostrou maior no aglomerado JVP, em virtude do alongamento de sua forma, da variabilidade altimétrica e da influência do sistema viário.

A forma urbana com tendência à circularidade observada em SJRP apresentou maiores valores de $\mathrm{D}$, com menor variabilidade, considerando-se o afastamento a partir do centro urbano. Este comportamento relacionou-se também à quase inexistência de impedâncias espaciais no crescimento urbano desta cidade.

A análise do preenchimento urbano das duas cidades, situadas em diferentes compartimentos geomorfológicos, mostrou que os aspectos físico-geográficos ainda exercem influência na morfologia urbana, embora novas intervenções espaciais sejam possíveis, a partir dos avanços tecnológicos atuais. O uso e a ocupação das proximidades da borda caracterizam o processo de dispersão urbana, à medida que concentram áreas ainda não ocupadas, que podem constituir especulação imobiliária. A ocorrência de maior concentração de áreas não urbanizadas nas bordas confirma a baixa densidade de ocupação, periférica à mancha urbana principal.

Ao contrário de uma cidade fragmentada e dispersa, uma cidade mais compacta permitiria a redução de distâncias em deslocamentos, estimularia pedestres e ciclistas, aumentaria a qualidade e distribuição de sistemas coletivos de transporte, os quais representam maior eficiência no consumo de energia e menor emissão de poluentes (RIBEIRO; SILVEIRA, 2012).

A intensidade da fragmentação urbana, sobretudo nas áreas periféricas às manchas urbanas, pode resultar em maiores dificuldades de acesso e distribuição dos serviços à comunidade. Em vista dos resultados obtidos, sugere-se a utilização, para futuros trabalhos, de imagens com maior resolução espacial, que permitam maior detalhamento da forma urbana, considerando os vazios urbanos.

A dimensão fractal utilizada na série temporal das duas áreas urbanas revelou-se de grande utilidade neste estudo, uma vez que permitiu monitorar a evolução das formas urbanas quanto ao seu preenchimento e possibilitou relacionar 
o comportamento setorial das formas urbanas às características físico-geográficas e antrópicas de ambos os sítios urbanos.

\section{REFERÊNCIAS}

ASTER Global Digital Elevation Model (ASTER GDEM). http://www.gdem.aster.ersdac.or.jp/: 10 de setembro de 2009.

BATTY, M; FOTHERINGHAM, A. S.; LONGLEY, P. Fractal geometry and morphology. In: DE COLA, L.; LAM, N. S. Fractals in Geography. Nova Jersey: Prentice Hall. pp. 228-246, 1993.

BATTY, M.; LONGLEY, P. Fractal cities: a geometry of form and function. London: Academic Press, 1994.

BERRY, B. J. Approaches to regional analysis: a synthesis. Annals of the Association of American Geographers, v. 54, n. 1, pp. 2-11, 1964.

DE COLA, L.; LAM, N. S. Introduction to fractals in Geography. In: Lam, N. S.; De Cola, L. Fractals in Geography. Caldwell: The Blackburn Press. p. 3-22, 1993.

DEPARTAMENTO DE ESTRADAS E RODAGEM. DER. Mapas das Diretorias de Planejamento. São Paulo: 2009. Um Mapa. Escala 1:250.000.

EWING, R. H. Characteristics, Causes, and Effects of Sprawl: A Literature Review. Environmental and Urban Studies, v. 21, n. 2, pp. 1-15, 1994.

FRANKHAUSER, P. La fractalité des structures urbaines. Paris: Anthropos, 1994.

FRANKHAUSER, P. The fractal approach. A new tool for the spatial analysis of urban agglomerations. Population, v. 10, n. 1, pp. 205-240, 1998.

FURTADO, C. O longo amanhecer: reflexões sobre a formação do Brasil. Rio de Janeiro: Paz e Terra, 1999.

GOODCHILD, M. F.; MARK, D. M. The fractal nature of geographic phenomena. Annals of the Association of American Geographers, v. 77, n. 2, pp. 265-278, 1987. 
HEROLD, M.; COUCLELIS, H.; CLARKE, K. C. The role of spatial metrics in the analysis and modeling of urban land use change. Computers, Environment and Urban Systems, v. 29, pp. 369-399, 2005.

INSTITUTO NACIONAL DE PESQUISAS ESPACIAIS. INPE. Catálogo de Imagens. Satélite LANDSAT TM 5. São José dos Campos: INPE, 1985; 1995; 2005. 6 cenas. Órbitas/ponto: 219/76; 221/74. http://www.dgi.inpe.br/CDSR/.

INSTITUTO NACIONAL DE PESQUISAS ESPACIAIS. INPE. Catálogo de Imagens. Satélite CBERS 2B. São José dos Campos: INPE, 2008. 5 cenas. Órbitas/ponto: 158(E)/123(4); 154(A)/126(2); 154(A)/126(3); 154(B)/126(2); 154(B)/126(3). http://www.dgi.inpe.br/CDSR/.

INSTITUTO DE PESQUISAS TECNOLÓGICAS DO ESTADO DE SÃO PAULO. IPT. Mapa geomorfológico do Estado de São Paulo. São Paulo: IPT, vol. II, (Publicação IPT 1183). Escala 1:1.000.000. 1981.

INSTITUTO GEOGRÁFICO E GEOLÓGICO. IGG. Mapeamento dos municípios do estado de São Paulo. São Paulo: IGG/Secretaria da Agricultura, Indústria e Comércio, Um Mapa. Escala 1:100.000. 1938.

JUNDIAÍ. Prefeitura. Secretaria. Secretaria de Planejamento e Meio Ambiente. Mapa do Município de Jundiaí. Secretaria de Planejamento e Meio Ambiente: Um mapa. Escala aproximada 1:30.000. 1940.

LONGLEY, P. A; MESEV, V. Measurement of density gradients and space-filling in urban systems. Papers in Regional Science, v. 81, pp. 1-28, 2002.

MARQUES, M. L.; FERREIRA, M. C. Análise da densidade de ocupação do aglomerado urbano da região metropolitana de São Paulo pela estimativa de dimensão fractal. Geografia, v. 31, n. 2, pp. 293-316, 2006.

MARQUES, M. L.; FERREIRA, M. C. Análise direcional do crescimento urbano da região metropolitana de São Paulo entre 1905 e 2001, utilizando-se a dimensão fractal. Revista do Programa de Pós-Graduação da Faculdade de Arquitetura e Urbanismo da Universidade de São Paulo, n. 23, pp. 100-118, 2008.

MATTOS, E. C. A. de.; FERREIRA, M. C. Dinâmica espaço-tempo do uso e ocupação do solo na região de entorno à área urbana de Jundiaí/SP: implicações 
futuras na Reserva Biológica da serra do Japi. In: Simpósio Brasileiro de Sensoriamento Remoto, 13. (SBSR), Florianópolis. Anais... São José dos Campos: INPE. pp. 2849-2856, 2007.

ORGANIZAÇÃO DAS NAÇÕES UNIDAS. ONU. A ONU e a população mundial. http://www.onu.org.br/a-onu-em-acao/a-onu-em-acao/a-onu-e-a-populacao-mundial/: 4 de outubro de 2011.

RIBEIRO, E. L.; SILVEIRA, J. A. R. da. O fenômeno do sprawl urbano e a dinâmica de segregação socioespacial. Revista Arquitetura e Urbanismo. http://www.revistaau.com.br/arquitetura-urbanismo/185/o-fenomeno-do-sprawlingurbano-por-edson-leite-ribeiro-e-149628-1.asp: 11 de outubro de 2012.

RODRIGUES, M. R. B. A Forma Urbana em Portugal Continental: Aplicação de Índices Quantitativos na Caracterização Morfológica das Cidades. 147f. Dissertação (Mestrado em Sistemas de Informação Geográfica e Modelação Territorial Aplicados ao Ordenamento) - Universidade de Lisboa, Lisboa, 2009.

SÃO PAULO (Estado). Fundação Sistema Estadual de Análise de Dados. SEADE. São Paulo no limiar do século XXI - Cenários da urbanização paulista. São Paulo: Fundação Seade, 106p. Vol. 5. 1992.

SÃO PAULO (Estado). Fundação Sistema Estadual de Análise de Dados. SEADE. Informações dos Municípios Paulistas. http://www.seade.gov.br/produtos/imp/index.php: 25 de maio de 2011.

SERRA, G. O espaço natural e a forma urbana. São Paulo: Nobel, 1987.

SINGER, P. Desenvolvimento econômico e evolução urbana. São Paulo: Nacional, 1977.

TANNIER, C.; PUMAIN, D. Fractals in urban geography: a theoretical outline and an empirical example. Cybergeo: European Journal of Geography [En ligne], Systèmes, Modélisation, Géostatistiques, document 307, mis en ligne le 20 avril 2005. http://www.cybergeo.eu/index3275.html. 2005.

TORRENS, P. M.; ALBERTI, M. Measuring Sprawl. Working Paper Series, n. 27, 2000. 

APLICAÇÃO DA DIMENSÃO FRACTAL

UN-HABITAT. State of world's cities 2010/2011: bridging the urban divide. London: Earthscan, 2008. 